\title{
Prediction of Cardiovascular Disease in suburban population of 3 municipalities in Nepal
}

\author{
Koju R, Gurung R, Pant P, Humagain S, Yogol CM, Koju A, Manandhar K, Karmacharya B, Bedi TRS
}

\section{Address for Correspondence:}

Rajendra Koju

Department of Medicine

Dhulikhel Hospital, Kathmandu University Hospital

koju@mos.com.np

\section{Abstract \\ Background}

Cardiovascular disease (CVD) is a major cause of morbidity and mortality throughout the world including Nepal. The assessment of risk factors responsible for CVD can predict 10 year risk of CVD. World Health Organization (WHO) risk assessment chart, specially designed for South East Asia Sub-region D can predict the risk of CVD in Nepal.

\section{Method and Materials}

A total 532 study population from Panauti, Banepa and Dhulikhel were calculated their 10 year risk of CVD using WHO/ISH risk prediction chart on the basis of risk factors: age, gender, smoking status, diabetes, systolic blood pressure and total cholesterol.

\section{Result}

Ten year risk of developing cardiovascular disease is less than $10 \%$ among the population less than 50 years, irrespective of gender. $5 \%$ of male population had more than $10 \%$ chance of developing cardiovascular events in next ten years. One third of $60-69$ years people had more than $10 \%$ chance of developing cardiovascular disease whereas it increased to $50 \%$ among 70 years and older group.

\section{Conclusion}

The assessment of risk factors is quite easy and cheap tool to predict the cardiovascular event, which support to practice the good clinical management to prevent the cardiovascular morbidity and mortality. 


\section{Introduction}

Cardiovascular diseases (CVD) are a major cause of morbidity and mortality throughout the world. Cardiovascular diseases are increasing rapidly in the developing world. ${ }^{1}$ With the development of diagnostic facilities and health care awareness in urban areas of Nepal, the numbers of cardiovascular diseases are increasing in trend according to different hospital data. The underlying pathology atherosclerosis, which develops over many years and is usually advanced by the time symptoms occur, generally in middle age. Coronary artery disease and cerebrovascular disease frequently occur suddenly and are often fatal before medical care can be given.

There are number of established measurable risk factors precede the cardiovascular events which are modifiable as well. Quantification of risk factors is particularly useful for the identification of high risk who are most likely to benefit from clinical management of risk factors ${ }^{2}$. Modification of such risk factors has been shown to reduce mortality and morbidity in people with diagnosed or undiagnosed cardiovascular disease. ${ }^{1}$

Assessment of risk factors can predict the future cardiovascular events. Since most of the risk assessment like Framingham Risk Score, British Society Chart, European Society of Cardiology, Coronary Risk Chart is mostly based upon the Caucasian population, which may not be exact with Asian population like Nepali. World Health Organization published the guidelines for assessment and management of cardiovascular risk for prevention in 2007, which is designed for South East Asia². This study was done to assess the risk factors to predict ten year risk of cardiovascular event in suburban population of Nepal using WHO/ISH risk assessment chart.

\section{Method and Materials}

A total of 930 people of more than 40 years from Panauti, Banepa and Dhulikhel Municipalities were selected from the voter list with stratified random sampling. They were visited in their home to take consent and study in fixed clinic in respective ward. Among them, 585 visited the preinformed fixed clinic for study. They were called in overnight fasting for 12 hours to check fasting blood glucose and total cholesterol. They were interviewed and examined by trained medical doctors and paramedics.

Blood pressure was measured using a standard mercury sphygmomanometer on the left arm after 5 min rest with the subject in the sitting position. The first and fifth phase of Korotkoff sounds were used for systolic (SBP) and diastolic blood pressures (DBP), respectively. Two independent measurements were taken with a minimal interval of
10 min. Dry chemistry tests was used to measure total cholesterol (TC) and fasting blood sugar level using the Accutrend GC system (Accutrend GC ${ }^{\circledR}$, Roche Diagnostics, Germany). In selected cases, an electrocardiogram (ECG) was recorded based on the discretion of the physician in order to confirm coronary heart disease.

The study population having history of established coronary artery disease, myocardial infarction, cerebrovascular disease, coronary revascularization and peripheral vascular disease were excluded for analysis to assess risk factors for future cardiovascular events. The total eligible 532 data was analyzed using SPSS 13.

The following risk factors were used to predict the future cardiovascular events,

$\checkmark$ Age

- Gender

- Smoking

- Systolic Blood Pressure

$\checkmark$ Diabetes

$\checkmark$ Total Cholesterol

Diabetes was defined when they were already diagnosed and/or taking antidiabetic medicine or fasting blood glucose more than $126 \mathrm{mg} / \mathrm{dl}$.

WHO/ISH risk prediction chart was used to analyze the data to predict future CVD events. The charts indicate total 10 year risk of a fatal or non fatal cardiovascular events (myocardial infarction or stroke), according to age, sex, blood pressure, presence or absence of diabetes, smoking status and cholesterol level for the WHO Region of South East Asia Subregion D which include Nepal'.

The 10 year risk is categorized into 5 subgroups;

- less than $10 \%$,

- $10-19.9 \%$,

- $20-29.9 \%$,

- $30-39.9 \%$,

$\checkmark \geq 40 \%$. 


\section{Year Risk Prediction Chart}

For People with Diabetes Mellitus

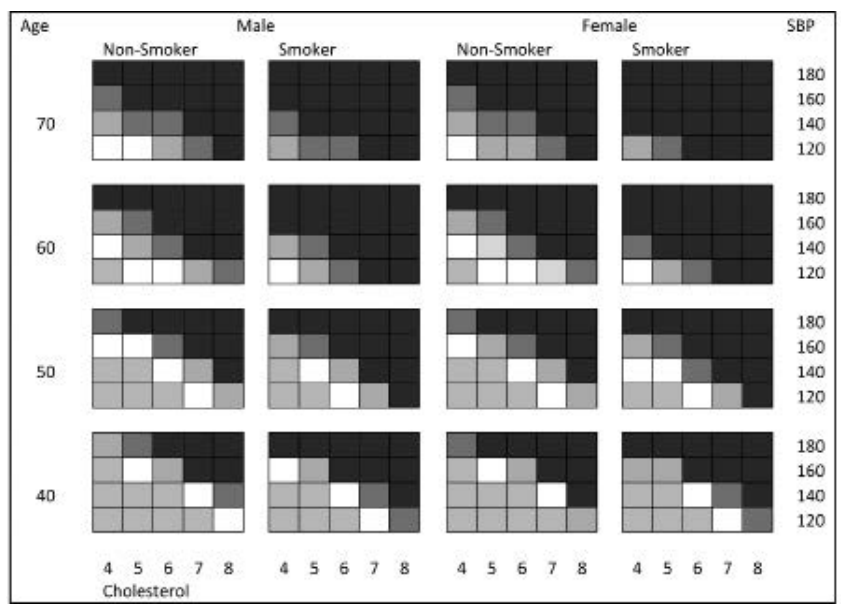

For People without Diabetes Mellitus

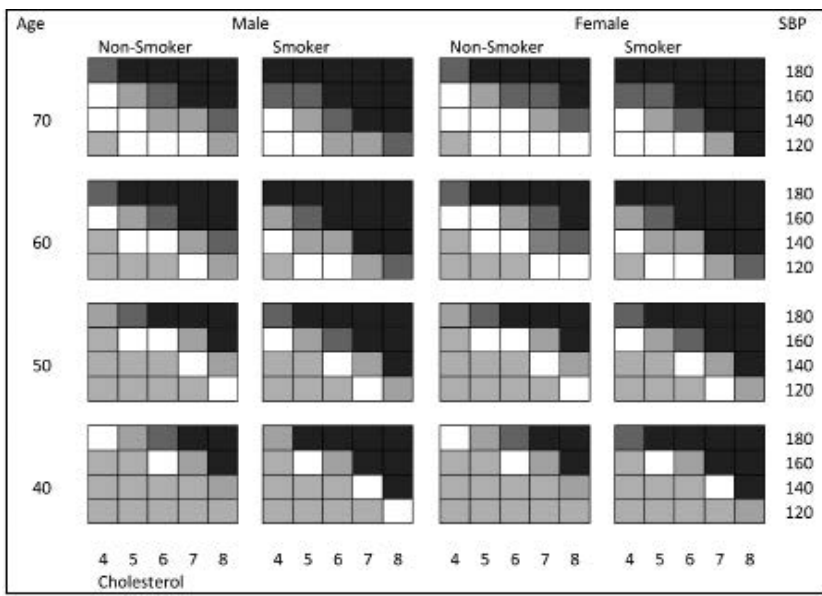

Key to risk leve

$\geq 40 \%$

$30-39.9 \%$

$20-29.9 \%$

$10-19.9 \%$

$<10 \%$

\section{Results}

A total 532 populations were analyzed for 10 year risk of fatal or nonfatal cardiovascular events according to WHO/ ISH risk prediction chart. Majority of the study populations were $40-59$ age group with about $51 \%$ of female. $29.3 \%$ of them were smoker and $3.4 \%$, diabetic and $24 \%$ were hypertensive. Majority of them had less than $4 \mathrm{mmol} / \mathrm{l}$ fasting cholesterol.
Table 1: Percentage of population with individual risk factors

\begin{tabular}{|c|c|}
\hline \multicolumn{2}{|c|}{ Age (in Years) } \\
\hline $40-49$ & (207) $38.9 \%$ \\
\hline $50-59$ & (169) $31.8 \%$ \\
\hline $60-69$ & (128) $24.1 \%$ \\
\hline 70 above & (28) $5.2 \%$ \\
\hline \multicolumn{2}{|c|}{ Gender } \\
\hline Male & (261) $49.1 \%$ \\
\hline Female & (271) $50.9 \%$ \\
\hline \multicolumn{2}{|c|}{ Smoking Status } \\
\hline Smoker & (156) $29.3 \%$ \\
\hline Nonsmoker & (376) $70.7 \%$ \\
\hline \multicolumn{2}{|c|}{ Diabetes } \\
\hline Diabetic & (18) $3.4 \%$ \\
\hline Nondiabetic & (514) $96.6 \%$ \\
\hline \multicolumn{2}{|c|}{ Systolic Blood Pressure (in $\mathrm{mmHg}$ ) } \\
\hline 120 & (406) $76.3 \%$ \\
\hline 140 & (94) $17.7 \%$ \\
\hline 160 & (25) $4.7 \%$ \\
\hline 180 & (7) $1.3 \%$ \\
\hline \multicolumn{2}{|c|}{ Total Cholesterol (in $\mathrm{mmol} / \mathrm{l}$ ) } \\
\hline 4 and less & (442) $83.1 \%$ \\
\hline 5 & (64) $12 \%$ \\
\hline 6 & (17) $3.2 \%$ \\
\hline 7 & (8) $1.5 \%$ \\
\hline 8 & (1) $0.2 \%$ \\
\hline
\end{tabular}

Table 2: Smoking status

\begin{tabular}{|l|l|l|}
\hline & Smoker & Nonsmoker \\
\hline Male & $(100) 38.3 \%$ & $(161) 61.8 \%$ \\
\hline Female & (56) $20.7 \%$ & $(215) 79.3 \%$ \\
\hline
\end{tabular}

The risk was calculated using the risk prediction chart on the basis of all 6 individual risk factors. Ten year risk of developing cardiovascular disease is less than $10 \%$ among the population less than 50 years, irrespective of gender. $5 \%$ of male population had more than $10 \%$ chance of developing cardiovascular events in next ten years. One third of $60-69$ years people had more than $10 \%$ chance of developing cardiovascular disease whereas it increased to $50 \%$ among 70 years and older group.

Table 3: Proportion of the study population in different risk category with ( $n=532$ )

\section{Male Population}

\begin{tabular}{|c|c|c|c|c|}
\hline Risk Category & \multicolumn{4}{|c|}{ Age group (in Years) } \\
\hline & $<50$ & $50-59$ & $60-69$ & $70+$ \\
\hline$<10 \%$ & $\begin{array}{c}(97) \\
100 \%\end{array}$ & $\begin{array}{l}(76) \\
95 \%\end{array}$ & $\begin{array}{c}(50) \\
76.90 \%\end{array}$ & $\begin{array}{c}\text { (9) } \\
47.40 \%\end{array}$ \\
\hline $10-19.9 \%$ & & $\begin{array}{c}(3) \\
3.80 \%\end{array}$ & $\begin{array}{c}(11) \\
16.90 \%\end{array}$ & $\begin{array}{c}\text { (9) } \\
47.40 \%\end{array}$ \\
\hline $20-29.9 \%$ & & $\begin{array}{c}(1) \\
1.20 \%\end{array}$ & & $\begin{array}{c}(1) \\
5.30 \%\end{array}$ \\
\hline $30-39.9 \%$ & & & $\begin{array}{c}(3) \\
4.60 \%\end{array}$ & \\
\hline$\geq 40 \%$ & & & $\begin{array}{c}(1) \\
1.50 \%\end{array}$ & \\
\hline
\end{tabular}


Female Population

\begin{tabular}{|c|c|c|c|c|}
\hline Risk Category & \multicolumn{4}{|c|}{ Age group (in Years) } \\
\hline & $<50$ & $50-59$ & $60-69$ & $70+$ \\
\hline$<10 \%$ & $\begin{array}{l}(110) \\
100 \%\end{array}$ & $\begin{array}{c}(89) \\
100 \%\end{array}$ & $\begin{array}{l}(46) \\
73 \%\end{array}$ & $\begin{array}{c}(4) \\
44.40 \%\end{array}$ \\
\hline $10-19.9 \%$ & & & $\begin{array}{l}(12) \\
19 \%\end{array}$ & $\begin{array}{c}(2) \\
22.20 \%\end{array}$ \\
\hline $20-29.9 \%$ & & & $\begin{array}{c}(2) \\
3.20 \%\end{array}$ & $\begin{array}{c}(1) \\
11.10 \%\end{array}$ \\
\hline $30-39.9 \%$ & & & $\begin{array}{c}(2) \\
3.20 \%\end{array}$ & $\begin{array}{c}(1) \\
11.10 \%\end{array}$ \\
\hline$\geq 40 \%$ & & & $\begin{array}{c}(1) \\
1.60 \%\end{array}$ & $\begin{array}{c}(1) \\
11.10 \%\end{array}$ \\
\hline
\end{tabular}

\section{Discussion}

Cardiovascular disease is preceded by measurable risk factors like age, gender, presence or absence of diabetes, smoking status, systolic blood pressure, cholesterol level. These risk factors have causative relation with atherosclerosis which is the basis of cardiovascular disease. The person having these risk factors are more likely to develop cardiovascular disease than those who do not have these risk factors. Although individual risk factor is related with cardiovascular event, the combined approach of risk factors can better predict the outcome. ${ }^{2}$

The burden of cardiovascular disease has been increasing in this part of world. The Indian subcontinent (including India, Pakistan, Bangladesh, Sri Lanka, and Nepal) is home to 20 percent of the world's population and may be one of the regions with the highest burden of CVD in the world..$^{3-5}$ However, less attention has been paid to the enormous burden of CVD in this region. ${ }^{6}$

In $2007 \mathrm{WHO} / \mathrm{ISH}$ published the risk prediction chart for CVD for different WHO subregions. This provided a simple tool to do the risk prediction for CVD. This is particularly of great use for the low-income settings as in the South East Asia Region. This chart uses the risk factors of age, gender, smoking status, diabetes mellitus, systolic blood pressure and cholesterol level. These risk factors are easily available to be assessed in low income countries as well. Ten year risk of cardiovascular event in 532 people of suburban areas of Nepal has been calculated using this chart.

The risk of development of cardiovascular event in 10 years is less than $10 \%$ among the age group less than 50 years. This age group was found to have no risk factor or single risk factor in most of the cases. This finding correlates with the WHO calculation that has shown that nearly $98 \%$ of the people of this age group will have less than $10 \%$ risk where as only $2 \%$ will have more than $10 \%$ risk of development of CVD in 10 years $^{2}$.
Increasing age along with other risk factors causes more risk for cardiovascular event. $5 \%$ male people of $50-59$ years age group has more than $10 \%$ risk of developing CVD events which is less than WHO calculation, which is about $17 \%$. All female population of this age group has less than $10 \%$ risk.

More than $6 \%$ population of $60-69$ years age group has more than $20 \%$ risk of CVD events. $55 \%$ people of 70 years above have more than $20 \%$ risk for CVD event. $22 \%$ of female population of 70 years above has more than $30 \%$ risk of CVD event.

The risk category of the 60-69 and 70+ aged subjects in this study shows that, the proportion of people in higher risk groups is lower than that shown in WHO chart ${ }^{2}$. There is a relative dearth of studies done on this matter in this region. The differences in different communities and also in the people of urban, sub-urban and rural areas have not been studied so far. Larger multi-centric studies incorporating people from diverse socio-economic background will reveal more accurate findings that can be generalized to the population as a whole.

\section{Conclusion}

The assessment of risk factors and risk prediction of CVD using the WHO chart is quite easy and cheap tool to predict the cardiovascular event. This also helps in the planning and implementation of preventive activities related to cardiovascular diseases. Although this study is from a small population of the adjoining three municipalities, this gives a small glimpse of the CVD risk scenario of Nepalese people. Though the findings can not be used to argue the overall case of Nepal, it definitely gives a ground that obviously a big proportion of the population may be exposed to the CVD risk factors, warranting an urgent need of actions to address this problem. 


\section{References}

1. Reddy KS, Yusuf S. Emerging epidemic of cardiovascular disease in developing countries. Circulation 1998; 97: 596601

2. Prevention of Cardiovascular Disease: Guidelines for assessment and management of cardiovascular risk. World Health Organization 2007.

3. Anand SS, Yusuf S, Vuskan V, Devanesen S, Teo KK, Montague $\mathrm{PA}$, et al. Differences in risk factors, atherosclerosis, and cardiovascular disease between ethnic groups in Canada: the Study of Health Assessment and Risk in Ethnic groups (SHARE). Lancet 2000; 356: 279-84

4. Mc Keigue PM, Miller GJ, Marmot MG. Coronary heart disease in South Asians overseas: a review. J CLin Epidemiol 1989; 42: 597-609

5. Enas EA, Yusuf S, Mehta JL. Prevalence of coronary artery disease in Asian Indians. Am J Cardiol 1992; 70: 945-9

6. Goyal A, Yusuf S. The burden of cardiovascular disease in the Indian subcontinent. Indian J Med Res 2006; 124: 235-244 